\title{
Tevatron Injection Timing
}

\author{
S. Saritepe and G. Annala \\ Fermi National Accelerator Laboratory \\ P.O. Box 500, Batavia, Illinois 60510
}

June 1993 


\section{Disclaimer}

This report was prepared as an account of work sponsored by an agency of the United States Government. Neither the United States Government nor any agency thereof, nor any of their employees, makes any warranty, express or implied, or assumes any legal liability or responsibility for the accuracy, completeness, or usefulness of any information, apparatus, product, or process disclosed, or represents that its use would not infringe privately owned rights. Reference herein to any specific commercial product, process, or service by trade name, trademark, manufacturer, or otherwise, does not necessarily constitute or imply its endorsement, recommendation, or favoring by the United States Government or any agency thereof. The views and opinions of authors expressed herein do not necessarily state or reflect those of the United States Government or any agency thereof. 


\title{
Tevatron Injection Timing
}

\author{
S. Saritepe* and G. Annala \\ Fermi National Accelerator Laboratory ${ }^{\dagger}$ \\ Batavia, Illinois, USA
}

June 25, 1993

\section{Introduction}

Bunched beam transfer from one accelerator to another requires coordination and synchronization of many ramped devices. During collider operation timing issues are more complicated since one has to switch from proton injection devices to antiproton injection devices. Proton and antiproton transfers are clearly distinct sequences since protons and antiprotons circulate in opposite directions in the Main Ring (MR) and in the Tevatron. The time bumps are different, the kicker firing delays are different, the kickers and lambertson magnets are different, etc.

Antiprotons are too precious to be used for tuning purposes, therefore protons are transfered from the Tevatron back into the Main Ring, tracing the path of antiprotons backwards. This tuning operation is called "reverse injection". Previously, the reverse injection was handled in one supercycle. One batch of uncoalesced bunches was injected into the Tevatron and ejected after 40 seconds. Then the orbit closure was performed in the MR. In the new scheme the lambertson magnets have to be moved and separator polarities have to be switched, activities that cannot be completed in one supercycle. Therefore, the reverse injection sequence was changed. This involved the redefinition of TVBS clock event \$D8 as MRBS \$D8 thus making it possible to inject 6 proton batches (or coalesced bunches) and eject them one at a time on command, performing orbit closure each time in the MR.

Injection devices are clock event driven. The TCLK is used as the reference clock. Certain TCLK events are triggered by the MR beam synchronized clock (MRBS) events. Some delays are measured in terms of MRBS ticks and MR revolutions. See Appendix A for a brief description of the beam synchronized clocks.

\section{Proton Injection in the Collider Mode}

Table 1 shows the clock events and the delays involved in the proton transfer during collider operations. Protons are injected into the $\mathrm{MR}$ at $\mathrm{A} 0$ and accelerated to $150 \mathrm{GeV}$ on a $\$ 2 \mathrm{~B}$ cycle. Proton injection into the Tevatron at $150 \mathrm{GeV}$ involves time bumps in the $\mathrm{MR}$ and in the Tevatron. FERMILAB TM-1790 [1] contains more details about the time-bumps involved in the beam transfer. In this note timing issues are stressed.

\footnotetext{
"current address: SSCL, MS 1040, 2550 Beckleymeade Ave. Dallas, TX 75237

tOperated by Universities Research Association,Inc., under contract with the United States Department of Energy
} 


\begin{tabular}{|l|l|l|}
\hline \hline \multicolumn{2}{|c|}{ PROTON INJECTION (COLLIDER) } \\
\hline $\begin{array}{l}\text { TCLK } \\
\text { Event }\end{array}$ & Delay & Description \\
\hline \hline 00 & & Supercycle reset \\
\hline 61 & $<00>0.1 \mathrm{sec}$ & DFG:Start \\
\hline 2B & TLG & Reset: MR cycle for collider (proton). \\
\hline $4 \mathrm{D}$ & TLG & Reset: Proton injection. \\
\hline 22 & $<2 \mathrm{~B}>0.6 \mathrm{sec}$ & MR:Start ramp to 150 GeV. \\
\hline 25 & $<2 \mathrm{~B}>2.5048 \mathrm{sec}$ & MR:Start of flattop at 150 GeV. \\
\hline & $<2 \mathrm{~B}>5.5 \mathrm{sec}$ & Start proton coalescing. \\
\hline & $<4 \mathrm{D}>7.0 \mathrm{sec}$ & $\begin{array}{l}\text { Start the MR time bump (M:MRD46, M:MRE17) } \\
\text { (these are now 465 cards) }\end{array}$ \\
\hline & $<4 \mathrm{D}>7.5 \mathrm{sec}$ & $\begin{array}{l}\text { Start the Tev time bump (handled by E0 465 } \\
\text { cards, see Operations Bulletin 1233) }\end{array}$ \\
\hline & $<4 \mathrm{D}>7.6 \mathrm{sec}$ & $\begin{array}{l}\text { Start the MR time bump (T:IBMP1, } \\
\text { T:IBMP2, T:IBMP3)(160 cards). }\end{array}$ \\
\hline
\end{tabular}

Sequencer complex command: "inject protons $\mathrm{Pn}$ " $(\mathrm{n}=1-6)$

\begin{tabular}{|l|l|l|}
\hline C1 & & $\begin{array}{l}\text { Align MRBS A-Marker with the TVBS A-Marker. } \\
\text { Occurs only once after "setting at } 150 \mathrm{GeV} \text { ". }\end{array}$ \\
\hline $\begin{array}{l}7 \mathrm{C} \rightarrow 5 \mathrm{C} \\
(\mathrm{MRBS})\end{array}$ & $<4 \mathrm{D}>13.80 \mathrm{sec}$ & Enable MRBS \$7C. \\
\hline & & Initiate MR $\rightarrow$ Tev transfer. \\
\hline & & Disable MRBS \$7C. \\
\hline
\end{tabular}

\begin{tabular}{|l|l|l|}
\hline & MRBS $<7 \mathrm{C}>2.044 \mathrm{mrev}$ & $\begin{array}{l}\text { Fire MR C48 kicker. Rise time is 360 nsec. } \\
\text { Flattop length } \approx 21 \mu \mathrm{sec} .\end{array}$ \\
\hline & MRBS $<7 \mathrm{C}>1.975 \mathrm{mrev}$ & $\begin{array}{l}\text { Fire Tev E17 kicker. Rise time is 550 nsec. } \\
\text { Flattop length 2-21 } \mu \mathrm{sec} \text { (adjustable). }\end{array}$ \\
\hline 26 & $\begin{array}{l}\text { These delays take into account the transit time } \\
\text { for the clock pulse to travel around the ring } \\
\text { and the position of the beam relative to the } \\
\text { clock pulse. }\end{array}$ \\
\hline
\end{tabular}

Table 1: Proton injection timing in the collider mode. The transfer cogging offsets are $0,186,371,557,742,928 \mathrm{RFCYC}$, for $\mathrm{P} 1$ through $\mathrm{P} 6$, respectively. Note that kickers are referenced to MRBS $\$ 7 \mathrm{C}$ not TCLK $\$ 5 \mathrm{C}$. 


\section{Antiproton Injection}

Antiprotons are injected into the MR at F17 and accelerated to $150 \mathrm{GeV}$ on $\$ 2 \mathrm{~A}$ cycles. Since the antiproton kicker in the MR (at E17) is a short distance away from E0, the time bump (T:IBMP1, T:IBMP2, T:IBMP3) is not necessary. Due to differences in the MR-C48 and MR-E17 kickers and due to the proximity of the MR-E17 Kicker to E0, the kicker timings are very different than the ones in $\$ 2 \mathrm{~B}$ cycle. The cogging offsets are also different.

In the transfer cogging there is no energy or path length manipulation in the Tevatron. The MR energy is manipulated, however, for this correction. The A-Marker of the MRBS is delayed with respect to the TVBS A-Marker. The TVBS A-Marker remains fixed with respect to Tev $R F$ while the $M R R F$ is phase shifted. Using transfer cogging offsets one can inject a proton or an antiproton bunch into a particular Tevatron bucket. The antiproton injection sequence is summarized in Table 2.

\section{Reverse Injection}

The antiproton injection line is tuned with protons by reverse injecting them from the Tevatron into MR. This simulates the forward antiproton injection. The reverse injection timing system has been changed. In the previous scenario, a single proton bunch was injected into the Tevatron on a $\$ 2 \mathrm{~B}$ cycle. The cogging offset for this bunch was 0 RFCYC. Forty seconds later in the supercycle, the same bunch was reverse injected into MR on a $\$ 20$ cycle. In the new timing scheme, six proton bunches can be injected into the Tevatron on six $\$ 2 B$ cycles, and then reverse injected into MR on six $\$ 20$ cycles on demand. The reverse injection request is issued by the sequencer.

Transfer cogging can only be done in the MR RF system. Therefore, a MRBS clock event has to fire the kickers for reverse transfer of protons. In the previous scenario, a TVBS clock event, $\$ \mathrm{D} 8$, was used. Since $\$ \mathrm{D} 8$ always came out in the same position relative to the TVBS A-Marker (revolution marker), only the first proton bunch, P1, could be ejected. The solution [2] was to make the \$D8 a MRBS clock event. So in the new scheme, one can change the time difference between the TVBS A-Marker and the $\$ D 8$ by changing the transfer cogging offset. The cogging offset can be set by the sequencer, providing reverse injection on demand. Any proton bunch can be selected. The reverse injection sequence is shown in Table 3.

\section{Proton Injection in the Fixed Target Mode}

In the fixed target mode, protons are accelerated to $150 \mathrm{GeV}$ on $\$ 21$ cycles. There is no coalescing and transfer cogging. The markers in the two machines are locked after MR and then a Tevatron bucket is labeled as bucket 1 . Then the MRBS event $\$ 78$ initiates the beam transfer. This sequence is shown in Table 4.

\section{Appendix A}

MRBS and TVBS: Beam synchronized clocks MRBS and TVBS are not really "beam synchronized". They are synchronized to RF frequencies. MRBS and TVBS generate a clock event AA (A-marker) at every $1113 \mathrm{RF}$ cycles which corresponds to 159 clock ticks (7 RF cycles $=1$ clock tick). The A-Marker is sometimes refered to as the "revolution marker". 


\begin{tabular}{|l|l|l|}
\hline \multicolumn{2}{|c|}{ ANTIPROTON INJECTION (COLLIDER) } \\
\hline $\begin{array}{l}\text { TCLK } \\
\text { Event }\end{array}$ & Delay & Description \\
\hline 00 & & Supercycle reset \\
\hline 61 & $<00>0.1 \mathrm{sec}$ & DFG:Start \\
\hline $2 \mathrm{~A}$ & TLG & Reset: MR cycle for collider (antiproton). \\
\hline 40 & TLG & Reset: Antiproton injection. \\
\hline 22 & $<40>0.6 \mathrm{sec}$ & MR:Start ramp to 150 GeV. \\
\hline 25 & $<40>2.5048 \mathrm{sec}$ & MR:Start of flattop at 150 GeV. \\
\hline & $<40>5.4 \mathrm{sec}$ & Start antiproton coalescing. \\
\hline & $<40>7.5 \mathrm{sec}$ & $\begin{array}{l}\text { Start the Tev time bump (handled by E0 } 465 \\
\text { cards, see Operations Bulletin 1233) }\end{array}$ \\
\hline
\end{tabular}

\begin{tabular}{|l|l|l|}
\hline C1 & \multicolumn{2}{|c|}{ Sequencer complex command: "inject pbars An" (n=1-6) } \\
\hline & CSBREQ request & $\begin{array}{l}\text { Align MRBS A-Marker with the TVBS A-Marker. } \\
\text { Occurs only once after "setting at 150 GeV". }\end{array}$ \\
\hline & 984 RFCYC & Start transfer cogging. \\
& 242 RFCYC & Cogging offset for AP1. \\
& Cogging offset for AP2. \\
& 427 RFCYC & Cogging offset for AP3. \\
& 613 RFCYC & Cogging offset for AP4. \\
& 798 RFCYC & Cogging offset for AP5. \\
& 56 RFCYC & Cogging offset for AP6. \\
& & Enable MRBS \$7B. \\
\hline 7 Initiate MR $\rightarrow$ Tev transfer. \\
$(\mathrm{MRBS})$ & $<40>13.80$ sec & \\
\hline & & Disable MRBS \$7B. \\
\hline
\end{tabular}

end "inject pbars An"

\begin{tabular}{|l|l|l|}
\hline & MRBS <7B $>0 \mathrm{mrev}$ & $\begin{array}{l}\text { Fire MR E17 kicker. Rise time is } 6 \mu \mathrm{sec} . \\
\text { It has a half-sine wave form. }\end{array}$ \\
\hline & MRBS $<7 \mathrm{~B}>2.396 \mathrm{mrev}$ & Fire Tev D48 kicker. Rise time is $3 \mu \mathrm{sec}$. \\
\hline 26 & $<2 \mathrm{~A}>13.9748 \mathrm{sec}$ & End of flattop $(150 \mathrm{GeV})$. \\
\hline
\end{tabular}

Table 2: Antiproton injection timing. Note that there is no IBMP for this cycle. The TCLK event $\$ 5 \mathrm{~B}$ disables $\$ 40$ and also triggers the Bull's Eye Plot. Kickers are referenced to MRBS $\$ 7 \mathrm{~B}$ not TCLK $\$ 5 \mathrm{~B}$. 
CP Cogging: The Collision Point (CP) cogging is accomplished by changing the antiproton path length. The cogging DF controller (CDFC) operates both CP cogging and transfer cogging therefore one cannot do $\mathrm{CP}$ cogging in the Tevatron while transfer cogging takes place in the MR RF system. The CP cogging rate cannot be varied, it is fixed at 2 buckets per second. Once initiated CP cogging always goes to completion [3]. The relevant parameters are:

T:ACPS specifies the magnitude and direction of CP cogging. The "t" retards the antiproton beam relative to the proton beam. The antiproton pathlength becomes longer than the proton pathlength. This is accomplished by decreasing the frequency of the antiproton $\mathrm{RF}$. The "." advances the antiproton beam relative to the proton beam by increasing the Frequency of the antiproton RF. The antiproton pathlength becomes shorter.

T:MCPS does fractional (RF bucket) CP cogging. The cogging is measured in mm units. T:MCPCOG starts the fractional bucket CP cogging.

\section{References}

[1] S.Saritepe and G.Annala, "Beam Transfer at E0: An Overview", FERMILAB-TM1790 (1993).

[2] R.J.Ducar, "Why TVBS \$D8 Became MRBS \$D8", Unpublished Note (July 1991).

[3] K.Meisner, "Console page M19, help subpage." 


\begin{tabular}{|l|l|l|}
\hline \hline \multicolumn{2}{|c|}{ REVERSE PROTON INJECTION } \\
\hline $\begin{array}{l}\text { TCLK } \\
\text { Event }\end{array}$ & Delay & Description \\
\hline \hline & Sequencer command & Disable \$4D. Wait 8 sec. \\
\hline 4B & Sequencer trigger & Tev:Abort clean-up \\
\hline & Sequencer command & Disable \$4B. \\
\hline \multicolumn{3}{|c|}{ Load sequencer files 10,13 } \\
\hline \multicolumn{3}{|c|}{ Inject 6 coalesced proton bunches into the Tevatron on 6 \$2B cycles } \\
\hline & Sequencer command & Tev:Move the proton lambertsons out. \\
\hline & Sequencer command & $\begin{array}{l}\text { Tev:Set the separator polarities to "-". } \\
\text { (C:C1SVP, C:B1SHP, C:B0SHP) }\end{array}$ \\
\hline C3 & Sequencer trigger & $\begin{array}{l}\text { Open the helix. } \\
\text { (Camac-465 tables are preloaded by C49) }\end{array}$ \\
\hline & Sequencer command & Insert \$20 cycles in the timeline. \\
\hline 20 & TLG & Reset: MR cycle for reverse injection. \\
\hline 22 & $<20>0.6$ sec & MR:Start ramp to 150 GeV. \\
\hline 25 & $<20>2.5048$ sec & MR:Start flattop at 150 GeV. \\
\hline & $<20>7.5$ sec & $\begin{array}{l}\text { Start the Tevatron time bump (handled by } \\
\text { E0 456 cards, see Operations Bull. 1233 }\end{array}$ \\
\hline
\end{tabular}

Sequencer complex command: "eject protons $\mathrm{Pn}$ " $(\mathrm{n}=1-6)$

\begin{tabular}{|l|l|l|}
\hline & & $\begin{array}{l}\text { Execute Sequencer file 35. This file sets up } \\
\text { MR BPM events to take data on \$20 cycle only. }\end{array}$ \\
\hline C1 & $\begin{array}{l}\text { Align MRBS A-Marker with the TVBS A-Marker. } \\
\text { Occurs only once after "setting at } 150 \mathrm{GeV} \text { ". }\end{array}$ \\
\hline $\begin{array}{l}\text { D8 } \rightarrow 55 \\
(\text { MRBS })\end{array}$ & $<20>13.8 \mathrm{sec}$ & Initiate Tev $\rightarrow$ MR transfer. \\
\hline & $<$ D8>2.038 mrev & Fire the Tev D48 kicker. Rise time is 3 $\mu$ sec. \\
\hline & $<$ D8>1.409 mrev & $\begin{array}{l}\text { Fire the MR E17 kicker. Rise time is 35 } \mu \text { sec. } \\
\text { Half-sine wave form. }\end{array}$ \\
\hline & & Disable \$D8. \\
\hline
\end{tabular}

end complex command "eject protons Pn"

\begin{tabular}{|l|l|l|}
\hline 26 & $<20>13.9748 \mathrm{sec}$ & MR:End of $\$ 20$ cycle flattop $(150 \mathrm{GeV})$ \\
\hline \multicolumn{3}{|c|}{ eject all 6 bunches, tune the antiproton injection line } \\
\hline C0 & Sequencer trigger & Close the helix. \\
\hline & Sequencer command & $\begin{array}{l}\text { Set C:C1SVP, C:B1SHP, C:B0SHP } \\
\text { polarities to "+". }\end{array}$ \\
\hline & Sequencer command & Move the proton lambertsons in. \\
\hline & Sequencer command & Remove the $\$ 20$ cycle from TLG. \\
\hline
\end{tabular}

Table 3: The new reverse injection timing. The transfer cogging offsets are $0,186,371,557,742,928 \mathrm{RFCYC}$, for $\mathrm{P} 1$ through $\mathrm{P} 6$ respectively. TCLK event $\$ 55$ triggers the Bull's Eye plot. 


\begin{tabular}{|c|c|c|}
\hline \multicolumn{3}{|c|}{ PROTON INJECTION (FIXED TARGET) } \\
\hline $\begin{array}{l}\text { TCLK } \\
\text { Event }\end{array}$ & Delay & Description \\
\hline$\overline{000}$ & & Supercycle reset \\
\hline 61 & $<00>0.1 \mathrm{sec}$ & DFG:Start \\
\hline 21 & TLG & Reset: MR cycle for fixed target. \\
\hline $4 \mathrm{D}$ & TLG & Reset: Proton injection. \\
\hline 22 & $<21>0.6 \mathrm{sec}$ & $\mathrm{MR}:$ Start ramp to $150 \mathrm{GeV}$. \\
\hline \multirow[t]{4}{*}{25} & $<21>2.5048 \mathrm{sec}$ & $\mathrm{MR}:$ Start flattop at $150 \mathrm{GeV}$. \\
\hline & $<4 \mathrm{D}>7.0 \mathrm{sec}$ & $\begin{array}{l}\text { Start the MR time bump (M:MRD } 46, \mathrm{M}: \mathrm{MRE} 17 \text { ). } \\
\text { (these are now } 465 \text { cards) }\end{array}$ \\
\hline & $\begin{array}{l}<4 \mathrm{D}>7.5 \mathrm{sec} \\
<4 \mathrm{D}>7.8 \mathrm{sec}\end{array}$ & $\begin{array}{l}\text { Start the T:IHTU,T:IHTD,T:IQUAD ramp } \\
\text { Start the MR time bump (T:IBMP1, } \\
\text { T:IBMP2, T:IBMP3)(160 cards) }\end{array}$ \\
\hline & $<4 \mathrm{D}>7.8 \mathrm{sec}$ & Start the Tevatron time bump. \\
\hline \multirow{4}{*}{$\begin{array}{l}78 \rightarrow 58 \\
(\mathrm{MRBS})\end{array}$} & $<4 \mathrm{D}>13.8 \mathrm{sec}$ & Initiate MR $\rightarrow$ Tev transfer. \\
\hline & MRBS $<78>2.044 \mathrm{mrev}$ & $\begin{array}{l}\text { Fire MR C48 kicker. Rise time is } 360 \text { nsec. } \\
\text { Flattop length } \approx 21 \mu \mathrm{sec} \text {. }\end{array}$ \\
\hline & MRBS $<78>1.975 \mathrm{mrev}$ & $\begin{array}{l}\text { Fire Tev E17 kicker. Rise time is } 550 \mathrm{nsec} \text {. } \\
\text { Flattop length } \approx 21 \mu \mathrm{sec} \text {. }\end{array}$ \\
\hline & & $\begin{array}{l}\text { These delays take into account the transit time } \\
\text { for the clock pulse to travel around the ring } \\
\text { and the position of the beam relative to the } \\
\text { clock pulse. }\end{array}$ \\
\hline
\end{tabular}

Table 4: Proton injection timing in the Fixed Target operation. 